\title{
Gastroenteropancreatic neuroendocrine tumors: recommendations of Turkish multidisciplinary neuroendocrine tumor study group on diagnosis, treatment and follow-up
}

\author{
Suayib Yalcin ${ }^{1}$, Fahri Bayram², Sibel Erdamar³, Ozlem Kucuk ${ }^{4}$, Nevin Oruc ${ }^{5}$, Ahmet Coker
}

\author{
${ }^{1}$ Department of Medical Oncology, Institute of Cancer, Hacettepe University, Ankara, \\ Turkey \\ ${ }^{2}$ Department of Endocrinology, Erciyes University, Kayseri, Turkey \\ ${ }^{3}$ Department of Pathology, Cerrahpasa Medical School, Istanbul, Turkey \\ ${ }^{4}$ Department of Nuclear Medicine, Ankara University, Ankara, Turkey \\ ${ }^{5}$ Department of Gastroenterology, Ege University, Izmir, Turkey
}

Submitted: 12 February 2015

Accepted: 20 May 2015

Arch Med Sci 2017; 13, 2: 271-282

DOI: https://doi.org/10.5114/aoms.2017.65449

Copyright $\odot 2017$ Termedia \& Banach

\begin{abstract}
Gastroenteropancreatic neuroendocrine tumors (GEPNETs) are a relatively rare, heterogeneous group of diseases in which important advances have been observed in the diagnosis and treatment as well as in our understanding of the biology and genetics of the disease in recent years. Given the insufficient scientific data available on evidence-based management of GEPNETs and the differences in circumstances in individual countries, a multidisciplinary study group was established to provide guidelines for the management of GEPNETS. This study group consisted of a medical oncologist, endocrinologist, surgeon, pathologist, gastroenterologist, and a nuclear medicine specialist, who aimed to prepare a practical guide in the light of existing scientific data and international guidelines, to be used in common clinical practice.
\end{abstract}

Key words: neuroendocrine tumor, guideline, consensus, diagnosis, treatment.

\section{Introduction}

Gastroenteropancreatic neuroendocrine tumors (GEPNETs) are a rare, heterogeneous group of tumors, most frequently located in the stomach, pancreas, small and large intestine, and rectum [1]. Since NETs may originate and effect various organ systems, a multidisciplinary approach including specialists from different medical fields is necessary. Therefore, an expert group, consisting of specialists from medical oncology, gastroenterology, endocrinology, nuclear medicine, pathology and surgery, was formed to establish a consensus report for the management of GEPNETs. Although there are several existing global guidelines, availability of treatment options and patient profiles may be different in individual countries, which creates a necessity to develop national guidelines in the light of existing global guidelines. The experts systematically reviewed the reported scientific data, international guidelines, and recently presented

\author{
Corresponding author: \\ Prof. Suayib Yalcin \\ Department of \\ Medical Oncology \\ Institute of Cancer \\ Hacettepe University \\ 06100 Ankara, Turkey \\ Phone: +90-505 3780639 \\ E-mail: suayibyalcin@gmail. \\ com
}


clinical trials, in order to prepare a set of practical recommendations for the multidisciplinary management of GEPNETs in Turkey [2-5].

\section{Epidemiology}

Gastroenteropancreatic neuroendocrine tumors may occur at any age; the highest incidence is among individuals $>50$ years of age. In patients with multiple endocrine neoplasia (MEN) type 1 or von Hippel-Lindau (VHL) or other genetic syndromes, the age at diagnosis is 15-20 years lower than those with sporadic GEPNETs. Although the incidence of cancer is decreasing overall, GEPNET incidence has been steadily increasing in the last few years, with an estimated incidence of $5.25 / 100,000$ in the year 2004 [6, 7]. Gastroenteropancreatic neuroendocrine tumor incidence is slightly higher in men compared to women $(5.35 / 100,000$ vs. $4.76 / 100,000)$. Currently, the general incidence of GEPNET is expected to reach $8 / 100,000$. The prevalence of the disease is however estimated to be much higher, and it ranks second after colorectal cancers among gastrointestinal tumors in the USA [7]. In Turkey, GEPNETs are not specifically included in the cancer registry system; therefore, incidence and prevalence data on GEPNETs are inadequate in Turkey. The GEPNET registry study data will provide multi-centric, both retrospective and prospective epidemiological data related to this disease in Turkey and in the region [8]. However, certainly it is necessary to develop a formal country-specific database for GEPNETs in Turkey. This registry system should be compatible with the European Neuroendocrine Tumor Society (ENETS) European Patient Registry system and the National Cancer Institute's Surveillance, Epidemiology, and End Results (SEER) tumor registry system so that the system may provide comparative data and help ensure its sustainability.

\section{Molecular biology}

There is a wide range of clinical and genetic variation between adenocarcinoma and neuroendocrine tumors of the pancreas. Although there are important differences between all GEPNET sub-types, it is practical to classify these tumors in 2 main groups - pancreatic NETs (PNETs) and gastrointestinal NETs (GI-NETs) - because PNETs and GI-NETs have different genetic and molecular biological characteristics $[9,10]$. Most of the GEPNETs are sporadic, however, they may be associated with familial genetic neuroendocrine tumor syndromes. The main types of these hereditary syndromes are MEN syndromes (MEN-1 and MEN-2), neurofibromatosis type $1, \mathrm{VHL}$ syndrome, tuberous sclerosis and Carney complex. The rec- ognition of these syndromes is not only important for proper patient management but can also help his/her family members to be identified for screening for GEPNETs and/or concomitant tumors and diseases. Mutations in the MEN-1 gene are seen not only in MEN-1 syndrome but also in sporadic PNETs as well. In fact, a $40 \%$ mutation rate of the MEN-1 gene has been reported in one study exploring PNETs. Similarly, genetic changes related to the ATRX/DAXX gene and the mammalian target of rapamycin (mTOR) pathway were also reported in PNETs. Moreover, there may be mutations in chromosome 18 in small intestine NETs. In a study with new generation gene sequencing, somatic mutation rates were found to be low in 48 patients with small intestine NETs; the analysis showed that the most frequent changes are found in the PI3K/Akt/mTOR signaling pathway, the transforming growth factor (TGF)- $\beta$ pathway (through alterations in SMAD genes), and the $S R C$ oncogene [11]. However, a genetic difference was not determined between sporadic and familial small intestine NETs. Among GEPNETs, genetic changes and carcinogenesis pathways are best clarified in MEN type 2 syndrome; activated mutations in the RET oncogene lead to the development of the tumor and this mutation demonstrates a genotype-phenotype correlation. Therefore, genetic counseling should be provided in suitable centers to identify cases with a possibility of familial inheritance, and multidisciplinary studies on genetic alterations relevant to the diagnosis and treatment of the disease should be supported.

\section{Pathology and diagnosis}

Gastroenteropancreatic neuroendocrine tumors show common phenotypic characteristics. Therefore, they show similar immunoreactivity to pan-neuroendocrine markers, chromogranin A and synaptophysin. Apart from these two markers, although less specific, neuron-specific enolase (NSE), CD56 and CD57 can be used to identify rectum NETs and poorly differentiated NETs.

All tumors diagnosed as GEPNETs should be graded based on the mitotic count and Ki-67 index $[12,13]$. Therefore, it is mandatory to determine the proliferation index by immunohistochemical assessment of Ki-67 (MIB-1) in the tumor tissue. For the pathological classification the WHO 2010 classification concerning the terminology of neuroendocrine tumor/carcinoma has been accepted (Tables I-IV) [1]. According to the WHO/ENETS grading system: mitosis $<2 / 10$ high power field (HPF) and/or Ki-67 $\leq 2 \%$ : grade 1 ; mitosis 2-20/10 HPF and/or Ki-67 3-20\%: grade 2; mitosis: > 20/20 HPF and/or Ki-67 > 20\% grade 3 (Tables I-IV) [12, 13]. 
Table I. NET grading

\begin{tabular}{|lccc|}
\hline Mitosis & Ki-67\% & ENETS/WHO & Grade \\
\hline$<2$ & $<3$ & NET & I \\
\hline $2-20$ & $3-20$ & NET & III \\
\hline$>20$ & $>20$ & NEC (small cell or large cells) & Mixed adenoendocrine carcinoma (MANEC) \\
\hline
\end{tabular}

Table II. ENETS and AJCC TNM staging for pancreatic NET

\begin{tabular}{|lcc|}
\hline & ENETS TNM & AJCC/UICC TNM \\
\hline T1 & Limited to pancreas, $<2 \mathrm{~cm}$ & Limited to pancreas, $<2 \mathrm{~cm}$ \\
\hline T2 & Limited to pancreas, $2-4 \mathrm{~cm}$ & Limited to pancreas, $>2 \mathrm{~cm}$ \\
\hline T3 & $\begin{array}{c}\text { Limited to pancreas }>4 \mathrm{~cm} \text {; or tumor invasion } \\
\text { of duodenum or common bile duct }\end{array}$ & $\begin{array}{c}\text { Tumor invasion of peripancreatic tissue. Not } \\
\text { involving major vascular invasion (truncus } \\
\text { coeliacus, A. mesenterica superior) }\end{array}$ \\
\hline T4 & $\begin{array}{c}\text { Tumor invasion of any adjacent structure or } \\
\text { involving major vascular invasion }\end{array}$ & Involving major vascular invasion \\
\hline
\end{tabular}

Table III. ENETS and AJCC TNM staging for Appendix

\begin{tabular}{|c|c|c|}
\hline & ENETS TNM & AJCC/UICC TNM \\
\hline $\mathrm{T} 1$ & Invasion of muscularis propria; $\leq 1 \mathrm{~cm}$ & $\begin{array}{l}\mathrm{T} 1 \mathrm{~A}: \leq 1 \mathrm{~cm} \\
\mathrm{~T} 1 \mathrm{~B}:>1-2 \mathrm{~cm}\end{array}$ \\
\hline $\mathrm{T} 2$ & $\begin{array}{c}\leq 2 \mathrm{~cm} \text { and }<3 \mathrm{~mm} \text { invasion of mesoappendix/ } \\
\text { subserous layer }\end{array}$ & $>2-4 \mathrm{~cm}$ or invasion of caecum \\
\hline T3 & $\begin{array}{c}>2 \mathrm{~cm} \\
>3 \mathrm{~mm} \text { invasion of mesoappendix/subserous layer }\end{array}$ & $>4 \mathrm{~cm}$ or invasion of ileum \\
\hline T4 & Invasion of peritoneum/other organ & Invasion of peritoneum/other organ \\
\hline
\end{tabular}

Table IV. ENETS and AJCC TNM staging for gastric NET

\begin{tabular}{|c|c|c|}
\hline & ENET & AJCC \\
\hline TX & Primary tumor cannot be assessed & Primary tumor cannot be assessed \\
\hline TO & No evidence of primary tumor & No evidence of primary tumor \\
\hline Tis & $<0.5 \mathrm{~mm}$ & Confined mucosa, $<0.5 \mathrm{~mm}$ \\
\hline $\mathrm{T} 1$ & Lamina propria or submucosa and $\leq 1 \mathrm{~cm}$ & $\begin{array}{l}\text { Tumor confined to mucosa and } 0.5 \mathrm{~mm} \text { or } \\
\qquad>1 \mathrm{~cm} \text { or } \\
\text { Invades submucosa and }<1 \mathrm{~cm}\end{array}$ \\
\hline $\mathrm{T} 2$ & Muscularis propria or subserosa or $>1 \mathrm{~cm}$ & Muscularis propria or $>1 \mathrm{~cm}$ \\
\hline T3 & Tumor penetrates serosa & Tumor invades subserosa \\
\hline T4 & Tumor invades adjacent structures & $\begin{array}{c}\text { Tumor invades visceral peritoneum (serosa) or } \\
\text { other organs or adjacent structures }\end{array}$ \\
\hline
\end{tabular}

All GEPNETs should be considered as potentially malignant, and the use of the term "benign" should be particularly avoided with GEPNETs. Immunohistochemical assessment of specific hormone expression is not routine in pathological evaluation. In addition, immunohistochemical detection of hormone expression in the tumor tissue (insulin, glucagon, vasoactive intestinal peptide (VIP) etc.) does not indicate that the tumor is functional.
Grading of the patients should be combined with organ specific TNM. There are some differences in the ENETS and WHO classifications, and the debate is on-going on this issue [14]. Accordingly, the below criteria considering the other current guidelines should be available in each pathology report [15]. Localization, size and invasion depth of the GEPNET, number of mitoses in $10 \mathrm{HPF}$ and Ki-67 score, immunophenotypic properties (at 
least chromogranin A and synaptophysin) and surgical margin of the excision/resection material should be included in the report.

Tumors classified as a single group as grade 3 tumors under the heading of neuroendocrine carcinoma using only the mitotic count and Ki67 rate as the determinant criteria may be well differentiated, poorly differentiated or undifferentiated histologically, and may have small or large cell morphology. Given the differences in the clinic course and treatment of these different entities, the cut-off values of the Ki-67 index and mitotic count should be revised in the near future $[16,17]$.

\section{Staging}

Staging and pathology reporting should be based on the WHO 2010 classification and the International Union Against Cancer (UICC) TNM $7^{\text {th }}$ edition (Tables I-IV) [18]. Organ specific TNM classifications by the WHO 2010 and ENETS classifications show differences regarding GEPNETs located in the stomach, appendix and pancreas. For GEPNETs originating from these organs, both ENETS and WHO 2010 classification systems can be used for reporting, but it should be indicated in the pathology report.

Somatostatin receptor imaging $\left({ }^{111} \mathrm{In}\right.$ Oct or preferably Ga-68) should be performed for preoperative staging in patients diagnosed with well-differentiated GEPNETs. Positron emission tomography (PET) - computed tomography (CT) imaging with Ga-68 labeled peptide is more sensitive than somatostatin receptor scintigraphy (SRS) and may change the clinical approach in $20-30 \%$ of the patients [19]. According to the localization of the primary tumor, CT and/or magnetic resonance imaging (MRI) should also be used for diagnosis and staging. Ultrasound and endoscopic ultrasound should be used when necessary as complementary examinations. Standard PET with 5-fluorodeoxyglucose (FDG) administration is not sensitive in well-differentiated GEPNETs, but can be used in diagnosis, staging and follow-up of aggressive, poorly differentiated GEPNETs [19-23]. In addition, it may be helpful to demonstrate the transformation to aggressive biological behavior $[24,25]$. The FDG uptake on FDG PET/CT is a powerful and independent prognostic factor in patients with neuroendocrine tumors. A prospective trial of 98 patients with neuroendocrine tumors demonstrated the strong prognostic value of presence and intensity of FDG uptake. Patients with FDG avidity were associated with a significantly higher risk of death (hazard ratio of 10.3) [26].

Thus far, the role of novel tracers in GEPNET has only been studied in clinical research and single center experience $[27,28]$.
Patients with GEPNET should have panendoscopy (esophagogastroduodenoscopy, colonoscopy, double-balloon enteroscopy and capsule endoscopy) performed according to the localization of the primary tumor, and also patients with an unknown primary tumor should have panendoscopy performed. In patients with GEPNETs of unknown primary site, the pancreas, appendix, ileum, lung and stomach should be examined first. These patients should primarily undergo MR enteroclysis, somatostatin receptor imaging with Ga-68, SRS and biopsy of suspected sites. If these methods do not yield to the detection of primary results, appropriate advanced tests should be performed.

\section{Treatment}

The site of primary disease (especially pancreatic and extrapancreatic origin), grade, stage and whether the disease is symptomatic (functional) or not are the primary factors important in treatment decision-making. Therefore, surgery, non-surgical local ablation methods, somatostatin analogues, interferon, chemotherapy, targeted agents and peptide receptor radionuclide therapy (PRRT) can be used in suitable patients $[6,29]$.

\section{Surgery}

Gastrointestinal NETs: Surgery is the only potentially curative treatment modality. Surgery should be considered for patients with early stage disease, in patients with locoregional and resectable metastatic disease, and in symptomatic patients. Surgery is the most effective method in the treatment of isolated liver metastases. Resection of the primary tumor and metastasectomy should primarily be considered in all suitable patients. Liver metastasectomy is the standard treatment in cases with 3 to 5 metastatic lesions limited to one lobe, and in those with multiple metastases with each metastatic lesion $<5 \mathrm{~cm}$ at suitable sites. In other circumstances, each patient should be individually evaluated. In some series including selected patients, the 5 -year survival rate reached up to $80 \%$. Primary tumor resection has a favorable effect on survival even in patients with unresectable metastatic disease because there is a risk for mesenteric fibrosis, obstruction, and vascular occlusion/thrombosis in small intestine NETs [30]. These patients are therefore suitable for primary tumor resection and lymph node dissection. However, small intestine resection may lead to short bowel syndrome.

Pancreatic NETs: Curative surgery with metastasectomy should also be considered in patients with metastatic PNETs that are potentially resectable. There is also evidence for the benefit of resection of the primary in patients with unresect- 
able hepatic metastases from PNETs as well [30]. The type of surgery for the pancreatic primary depends on the primary tumor site such as pancreatico-duodenal resection (Whipple surgery), distal pancreatic resection or resection in combination with enucleation. It is necessary to remove an adequate number of lymph nodes in these patients. Laparoscopic resection is not suitable because of the necessity of lymphadenectomy and attentive evaluation for invasion and metastasis.

G3 pancreatic tumors or poorly differentiated gastrointestinal neuroendocrine cell carcinomas (NECs) may not be suitable for surgery because these tumors generally show extensive metastasis at the time of diagnosis [29-32].

Surgery can also be beneficial in patients with local recurrence and for symptom control. However, surgery is available in only $20 \%$ of patients, and the recurrence rate after surgery is very high in metastatic disease. The benefits of adjuvant treatment after potentially curative surgery have still not been demonstrated. Although there are no studies examining adjuvant postoperative treatment in poorly differentiated or high grade NEC, their aggressive behavior justifies the use of adjuvant therapy in most cases. In this case cisplatin or carboplatin and etoposide combination chemotherapy is recommended. Sequential radiation can also be considered in cases where the risk of local recurrence is thought to be higher than usual [33].

Liver transplantation: The standards of liver transplantation have not yet been established. Five-year survival after liver transplantation is below $50 \%$, and disease-free survival is below $30 \%$. Recurrence rate, and morbidity and mortality rates are increased after liver transplantation. The best candidates for liver transplantation include patients below 55 years of age, patients with lowgrade tumors, resected primary tumors, tumors with liver invasion < 50\%, no extra-hepatic disease and those without disease progression in the last 6 months. The likelihood of extrahepatic lymphatic or vascular spread (for example to the distal rectum or lung) of the primary disease should not be high in these patients $[6,34,35]$.

\section{Non-surgical loco-regional therapy}

\section{Radiofrequency ablation (RFA)}

Radiofrequency ablation is used intraoperatively during percutaneous and laparoscopic interventions or during laparotomy in patients not suitable for metastasectomy. Although RFA can be used for lesions $<5 \mathrm{~cm}$, the best results are achieved in lesions with a maximum diameter of $3 \mathrm{~cm}$. There is no definite agreement on the number of lesions for which RFA can be applied. However, the chances of success decrease if there are more than 4 lesions. Radiofrequency ablation is not recommended for use if the number of lesions $>10$. Radiofrequency ablation can provide tumor and symptom control [36-39]. However, in patients with unfavorably located lesions or with previous Whipple surgery RFA should be used cautiously.

\section{Microwave/cryotherapy and percutaneous alcohol injection}

Microwave and cryotherapy are alternative local ablation methods that may be used in suitable centers by experienced teams. Percutaneous alcohol injection should not be considered if the other methods are available $[6,40]$.

\section{Transarterial embolization (TAE) and transarterial chemoembolization (TACE)}

Liver metastases of NETs are tumors characterized with high vascularization. Transarterial embolization (TAE) and transarterial chemoembolization (TACE) or radioembolization may decrease the tumor burden and hormone secretion in patients not suitable for surgery or RFA and medical treatment. In patients who show progression after systemic treatment, or in those whose symptom control cannot be maintained, TAE, TACE or radioembolization may be used depending on the individual patient characteristics and availability [41-48].

Transarterial chemoembolization is performed at 4-6 week intervals. In bilobar disease, stepwise embolization can be applied to each lobe. Most frequently, lipiodol, foam particles, iodinated contrast, and cyanoacrylate are used for embolization [41-43]. Superiority of beads used in TACE has not been demonstrated clearly. The objective response rates with TACE are widely variable; however, disease stabilization and symptom control rates are high. During TACE, a selected chemotherapy regimen such as doxorubicin, cisplatin, 5-fluorouracil and mitomycin- $C$ can be used via transarterial catheterization [41-44]. The most important complications in these patients are liver abscess, sepsis, pleural effusion, hepatorenal failure, and hepatic infarction. Moreover, as the risk of complication is greatly increased in patients with previous Whipple surgery, TACE should be performed only in selected conditions; it should not be used in the following conditions: massive or diffuse hepatic involvement, if metastasis involves > 50\% of the liver, hepatic failure, portal vein invasion, serum bilirubin $>2-3 \mathrm{mg} / \mathrm{dl}$ and serum transaminases $>100 \mathrm{lU} / \mathrm{l}$. Transarterial chemoembolization should be performed cautiously in patients with portal vein thrombosis and only suitable patients should be selected. Superselective embolization with low dose chemotherapy should be used in these patients [41-43]. 


\section{Radioembolization}

Radioembolization is also known as selective internal radiation therapy (SIRT). $Y^{90}$ embedded resin microspheres (SIR-Spheres, Sirtex Medical Ltd, Lane Cove, Australia) or $\mathrm{Y}^{90}$ embedded glass microspheres (TheraSphere, MDS Nordion Inc., Ontario, Canada) are infused through the hepatic artery [44-47]. Radioembolization can be used in unresectable lesions not suitable for RFA and in progressive liver metastasis unresponsive to medical treatment. The conditions necessary for radioembolization include sufficient liver reserve (bilirubin < 2-3 mg/dl, aspartate aminotransferase (AST) and alanine aminotransferase (ALT) $<5$ times, albumin $>3 \mathrm{mg} / \mathrm{dl}$ ), an ECOG performance status score $<2$, life expectancy $>3$ months, and normal prothrombin and partial thrombin time [42-45]. Its superiority to chemoembolization is debatable; however, it should be preferred to embolization or chemoembolization in patients with mild and moderate liver dysfunction or portal vein thrombosis, as it does not cause ischemic hepatitis [6, 45-48].

\section{Peptide receptor-radionuclide radiotherapy (PRRT)}

Peptide receptor-radionuclide radiotherapy can be used in patients with well-differentiated lowgrade NETs having positive somatostatin receptor imaging $[49,50]$. Better tumor responses are achieved with increased uptake of the radioactive peptide in the tumor. Radioisotope molecules that can be used for this purpose are primarily $\mathrm{Lu}^{177}$ and less frequently $Y^{90} \cdot \operatorname{In}^{111}$ is no longer preferred. ${ }^{177}$ Lu-DOTA-Tyr3-octreotate is preferred as it has less renal toxicity and higher sst2 affinity. PRRT can be considered independently from the primary tumor site in both functional and non-functional tumors. PRRT should be used when first line medical treatment is not successful in GI-NET but at later stages as a salvage after somatostatin analogues, targeted therapies (sunitinib/everolimus) and/or chemotherapy in PNET [6, 49]. However, response rates are higher in PNETs in comparison to small intestine NETs $[6,49,50]$.

\section{Medical treatment}

\section{Treatment of clinical symptoms}

Clinical symptoms may vary according to whether the tumor is functional or non-functional, and depending on the tumor's localization site and size. The main clinical symptoms are pain, obstruction, diarrhea, hypoglycemia symptoms, hyperglycemia, weight loss, and carcinoid syndrome findings. The majority of these findings can be eliminated by treatment of the tumor. If carcinoid syndrome symptoms are present, somatostatin analogues, interferon, symptomatic treatment for diarrhea, mTOR inhibition and other treatments can be applied [51-56].

\section{Somatostatin analogues}

As the half-life of natural somatostatin hormone is very short, somatostatin analogues with longer half-lives are currently used [51-53]. These are short- and long-acting octreotide and lanreotide. Pasireotide is also being studied in GEPNET patients [51]. Symptom control by somatostatin analogues improves the patient's quality of life, and enables the control of disease progression. For symptom control, short-acting somatostatin analogues at 100-150 $\mu \mathrm{g}$ doses should be used 2-3 times daily for at least 2 weeks; thereafter, monthly depot forms of somatostatin analogues (octreotide LAR 20-30 mg, lanreotide 60-120 mg) should be used. Short-acting forms should be continued for 2 additional weeks in these patients. If symptom control cannot be achieved, additional doses of short-acting somatostatin analogues can be used and the octreotide dose can be increased to $1500 \mu \mathrm{g}$ daily. Again, the dose of the depot form may gradually be increased (octreotide $40-60 \mathrm{mg}$ ) in these patients. Asymptomatic patients may receive the depot form of the drug directly [51-54].

Somatostatin analogues, octreotide LAR and lanreotide can be used in functional and non-functional small intestine tumors and well-differentiated PNETs for anti-proliferative purposes. Somatostatin analogues are the recommended first line of treatment in non-functional and functional progressive G1/G2 NETs. However, independent of the site of origin, somatostatin analogue treatment is not recommended in metastatic NEC G3. In addition, independent of the origin of the primary tumor and potential microscopic metastases, somatostatin analogues are not indicated in the adjuvant treatment of NET G1/G2. The Clarinet study showed the anti-tumor efficacy of somatostatin analogues in the treatment of non-functional tumors and PNETs [57-61].

\section{Interferon}

Interferon (IFN) has antiviral and anti-tumor activity; it has been used alone and in combination with chemotherapy and somatostatin analogues $[6,54,61,62]$. Interferon- $\alpha$ has been most widely studied. A pooled analysis of trials on IFN- $\alpha$ among patients with GEPNETs demonstrated that approximately $40 \%$ of patients had biochemical responses; the symptomatic response with IFN ranges from $40 \%$ to $70 \%$, which is comparable to that observed with octreotide and lanreotide [62]. The objective tumor response is approximately $10 \%$. Thus, while somatostatin analogues and IFN have similar effects on symptom control, IFN 
has greater anti-proliferative activity. However, IFN has a slow onset of action and poor favorable tolerability; therefore, IFN can be better used as a second-line approach in patients with functioning NETs and low proliferation. Combination of IFN- $\alpha$ with somatostatin analogues might have a synergistic effect; however, this combination has net been tested in large prospective studies, data come from a limited number of small studies, usually underpowered and with no prespecified primary endpoint. Furthermore, the clinical benefit of this synergistic effect may not be significant. Therefore, interferon-somatostatin analogue combination can be used only in some selected cases as salvage therapy, but not as a standard therapy $[61,62]$.

\section{Systemic treatment}

\section{Systemic chemotherapy}

Systemic chemotherapy is more effective in patients with a rapidly progressive disease or a tumor with a high proliferation rate and aggressive pathological features. Streptozotocin (STZ), chlorozotocin, 5-fluorouracil (5-FU), capecitabine, dacarbazine (DTIC), gemcitabine, temozolomide, and doxorubicin, as a single agent, are reported to have limited activity with response rates ranging from $0 \%$ to $50 \%$ [63-69].

Combination chemotherapy has been shown to be more effective than single agent chemotherapy in PNETs. Compared with STZ alone, 5-FU and STZ combination yielded a higher response rate $(36 \%$ vs. $63 \%)$ and a longer median survival rate $[70$, 71]. Furthermore, the addition of doxorubicin to STZ also improved the response rate in patients with advanced PNETs [72]. The response rate ranges from $8 \%$ to $60 \%$. In retrospective studies response rates reaching up to $70 \%$ with the temozolomide and capecitabine combination have been reported [73, 74]. In a more recent prospective phase II study a response rate of $43 \%$ was observed in a group of patients with well-differentiated NET including pancreas, gastrointestinal tract, pituitary and medullary thyroid tumor [75]. Likewise, oxaliplatin, irinotecan and fluoropyrimidine combinations can be used in the salvage treatment of GEPNETs, particularly in PNETs. However, randomized phase III studies are needed. Still, chemotherapy can be used as salvage therapy in selected patients with well-differentiated grade 1 gastrointestinal NETs and in patients with grade 2 tumors.

Cisplatin plus etoposide combination is the standard first-line treatment of poorly differentiated NETs, independent of the primary tumor site and whether it is a surgically excised grade 3 GEPNET, while the combinations of streptozoto- cin plus 5-FU or streptozotocin plus doxorubicin are usually suggested as a first-line treatment in well-differentiated NETs with disease progression $[76,77]$. Temozolomide plus capecitabine, irinotecan-based (irinotecan plus cisplatin or 5-FU) regimens can be used as second line treatment in patients with high grade PNETs [78, 79].

There is a strong need for data to define the role of adjuvant treatment in low or intermediate degree tumors that are surgically resected [6].

\section{Targeted treatments}

\section{mTOR inhibitors}

Mammalian target of rapamycin is a serine/ threonine protein kinase that is a part of the phosphatidylinositol 3' kinase (PI3K)-AKT signaling pathway. RADIANT-2, a randomized double-blind, placebo controlled, multicenter phase III study, evaluated the effects of octreotide combined with everolimus or placebo in patients with advanced NETs. After promising results with everolimus, RADIANT-3, a randomized double-blind, placebo controlled, multicenter phase III study of octreotide combined with everolimus or placebo in patients with advanced PNETs, was designed. Patients were randomized to receive either everolimus $10 \mathrm{mg} /$ day plus best supportive care or placebo plus best supportive care. The majority of the patients had well-differentiated or moderately differentiated tumors. Median progression-free survival (PFS) was 11.4 months in the treatment arm and 4.6 months in the placebo arm $(H R=0.35$; $p<0.0001)$. The most common side effects in the RADIANT trials were stomatitis followed by infections and pneumonitis. Therefore, the investigators concluded that everolimus is safe and well tolerable in patients with NETs [56, 80-82].

With the current available clinical data, use of everolimus at a dose of $10 \mathrm{mg} /$ day as a single agent is indicated in the first and second line treatment and salvage treatment of progressive well-differentiated (grade 1-2) PNETs. Although the endpoint stated in the study could not be reached in gastrointestinal NETs, everolimus can be used in the treatment of all well-differentiated neuroendocrine tumors if appropriate as suggested in the ESMO guidelines $[2,56]$.

\section{Tyrosine kinase inhibitors}

Sunitinib is a multi-targeted tyrosine kinase inhibitor, inhibiting VEGFR-1, -2, and -3, as well as platelet-derived growth factor (PDGF), KIT, and FLT3. A phase III study was performed to compare sunitinib at a continuous daily dose of $37.5 \mathrm{mg}$ to a placebo. The study, which was discontinued early following the planned interim analysis after the enrollment of 171 patients, demonstrat- 
ed a median PFS of 11.1 months in the sunitinib arm vs. 5.5 months in the placebo arm. The objective response rate in the sunitinib arm was $9.3 \%$ [83]. With these findings, sunitinib can be used in the treatment of well-differentiated PNETs with a Ki-67 score $\leq 5 \%$ as first-line, second-line and salvage treatment $[83,84]$. However, in a phase II study no definitive benefit was found in gastrointestinal NETs [85].

Pazopanib is an oral tyrosine kinase inhibitor targeting VEGFR, PDGFR and KIT with demonstrated clinical activity in NETs [86]. A phase II study showed that pazopanib might be clinically beneficial after everolimus and sunitinib use in the treatment of NETs [87].

Published data so far do not support the use of other tyrosine kinases such as sorafenib, gefitinib, imatinib or vatalanib in GEPNETs [88-95].

\section{Bevacizumab}

Bevacizumab is a monoclonal antibody which neutralizes vascular endothelial growth factor. Although data do not support the routine use of bevacizumab yet, it has been shown that it may be used in selected PNET cases [95]. Single agent efficacy of the other tested drugs, thalidomide and endostatin, has not been demonstrated [6].

\section{Response evaluation and follow-up}

The follow-up of patients who have been completely resected with surgery or endoscopy can be done at 3- to 6-month intervals. Response evaluation in those that receive systemic treatment should be performed at 3-month intervals [2]. The method that should be used depends on primary disease site, the course of the disease and the best imaging method at diagnosis [96]. In the routine follow-up of patients with no signs and symptoms of the disease, performance of SRS may be recommended at the earliest at 12 months; however, SRS should be used along with the oth er required methods in the treatment response evaluation and follow-up of advanced stage patients. Follow-up and response evaluation during PRRT should be done after staging at 12-month intervals. It is appropriate to perform scintigraphic

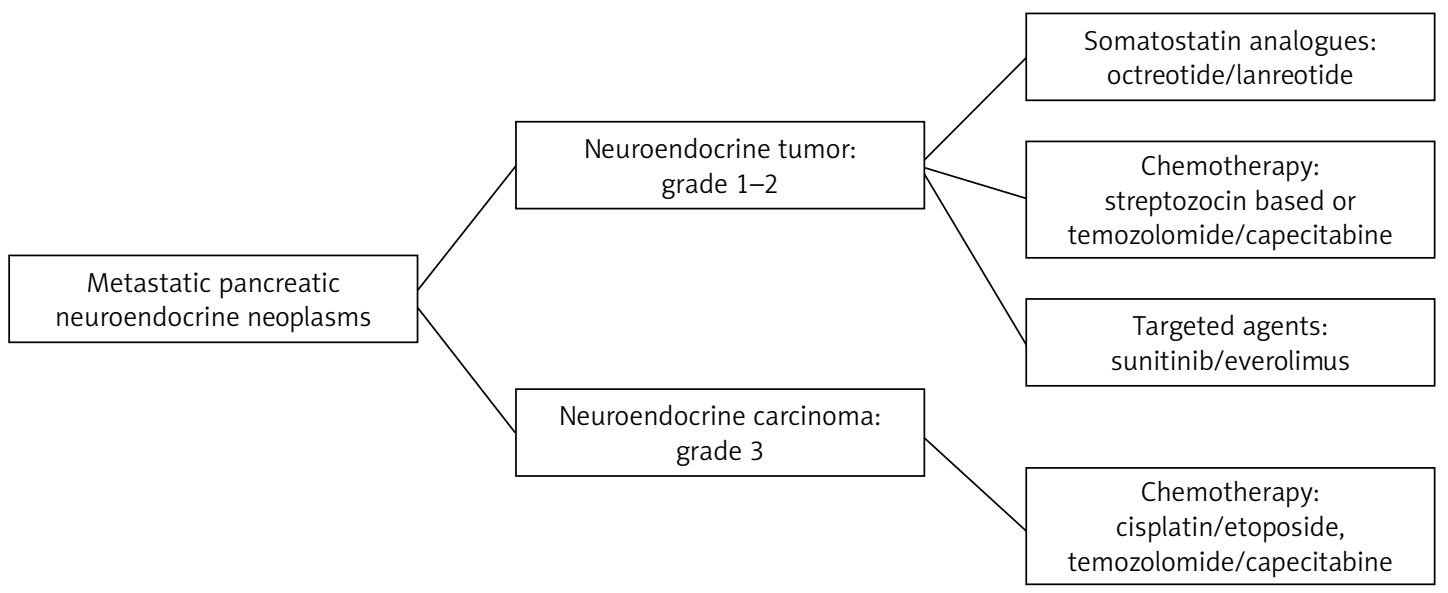

Figure 1. First line systemic treatment options for unresectable and/or metastatic pancreatic neuroendocrine neoplasms

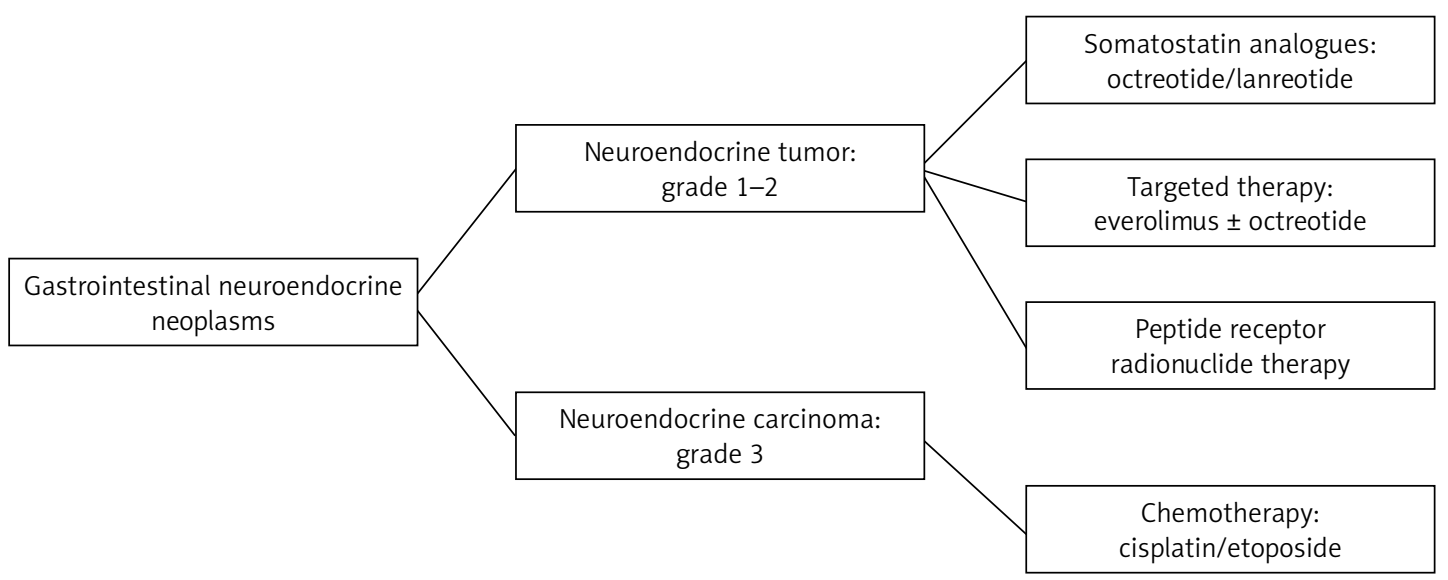

Figure 2. First line systemic treatment options for unresectable and/or metastatic gastrointestinal neuroendocrine neoplasms 
imaging at 3-month intervals for follow-up of the PRRT response so that the functional response can be determined before anatomic imaging $[96,97]$.

\section{Conclusions}

With the availability of newer treatment options improving survival in advanced NETs, treatment should be individualized depending on the prognostic and predictive factors (Figures 1, 2). Meanwhile there is no established adjuvant therapy after curative surgery, except for high grade NEC. All GEPNET patients should be evaluated, treated and followed in a multidisciplinary setting in experienced centers. Since these tumors are still considered as rare tumors, national and international patient registries are necessary to obtain further epidemiological and clinical data to improve our understanding of this heterogeneous disease.

\section{Conflict of interest}

Suayib Yalcin has had advisory board role in Novartis, Roche, Pfizer, Amgen and speaker Bureau role for Gen ilaç, Novartis, Roche, Pfizer and travel grant from Roche and Pfizer, and research grant from Celgene.

\section{References}

1. Rindi G, Arnold R, Bosman FT, et al. Nomenclature and classification of neuroendocrine neoplasms of the digestive system. In: WHO classification of tumours of the digestive system. Bosman FT, Carneiro F, Hruban RH, Theise ND (eds.). IARC Press, Lyon 2010; 13-4.

2. Öberg K, Knigge U, Kwekkeboom D, Perren A; ESMO Guidelines Working Group. Neuroendocrine gastro-entero-pancreatic tumors: ESMO Clinical Practice Guidelines for diagnosis, treatment and follow-up. Ann Oncol 2012; 23: 124-30.

3. Kunz PL, Reidy-Lagunes D, Anthony LB, et al. Consensus guidelines for the management and treatment of neuroendocrine tumors. Pancreas 2013; 42: 557-77.

4. Kulke MH, Benson AB 3rd, Bergsland E, et al. Neuroendocrine tumors. J Natl Compr Canc Netw 2012; 10: 724-64.

5. Salazar R, Wiedenmann B, Rindi G, Ruszniewski P. ENETS 2011 Consensus Guidelines for the management of patients with digestive neuroendocrine tumors: an update. Neuroendocrinology 2012; 95: 71-3.

6. Yalcin S. Advances in the systemic treatment of pancreatic neuroendocrine tumors. Cancer Treat Rev 2011; 37: 127-32.

7. Yao JC, Hassan M, Phan A, et al. One hundred years after "carcinoid": epidemiology of and prognostic factors for neuroendocrine tumors in 35,825 cases in the United States. J Clin Oncol 2008; 26: 3063-72.

8. Yalcin S, Glasberg S, Abali H, et al. Gastroenteropancreatic Neuroendocrine Tumors (GEPNET) Registry: Update from an International Collaboration Poster Discussion session (GEPNET) Registry. Ann Oncol (2014) 25 (Suppl4): iv394-iv405. 10.1093/annonc/mdu345.

9. Burnik FS, Yalcin S. NFKB1-94 insertion/deletion ATTG polymorphism in gastroenteropancreatic neuroendocrine tumors. Chemotherapy 2009; 55: 381-5.
10. Jiao Y, Shi C, Edil BH, et al. DAXX/ATRX, MEN1, and mTOR pathway genes are frequently altered in pancreatic neuroendocrine tumors. Science 2011; 331: 1199-203.

11. Banck MS, Kanwar R, Kulkarni AA, et al. The genomic landscape of small intestine neuroendocrine tumors. J Clin Invest 2013; 123: 2502-8.

12. Klöppel G, Couvelard A, Perren A, et al. ENETS Consensus Guidelines for the Standards of Care in Neuroendocrine Tumors: towards a standardized approach to the diagnosis of gastroenteropancreatic neuroendocrine tumors and their prognostic stratification. Neuroendocrinology 2009; 90: 162-6.

13. Pavel M, Baudin E, Covelard A, et al. ENETS Consensus Guidelines for the management of patients with liver and other distant metastases from neuroendocrine neoplasms of foregut, midgut, hindgut and unknown primary. Neuroendocrinology 2012; 95: 157-76.

14. Klimstra DS, Modlin IR, Coppola D, Lloyd RV, Suster S. The pathologic classification of neuroendocrine tumors: a review of nomenclature, grading, and staging systems. Pancreas 2010; 39: 707-12.

15. Klimstra DS, Modlin IR, Adsay NV, et al. Pathology reporting of neuroendocrine tumors: application of the Delphic consensus process to the development of a minimum pathology data set. Am J Surg Pathol 2010; 34: 300-13.

16. Vélayoudom-Céphise FL, Duvillard P, Foucan L, et al. Are G3 ENETS neuroendocrine neoplasms heterogeneous? Endocr Relat Cancer 2013; 20: 649-57.

17. Adsay V. Ki67 labeling index in neuroendocrine tumors of the gastrointestinal and pancreatobiliary tract: to count or not to count is not the question, but rather how to count. Am J Surg Pathol 2012; 36: 1743-6.

18. Rindi G, Falconi M, Klersy C, et al. TNM staging of neoplasms of the endocrine pancreas: results from a large international cohort study. J Natl Cancer Inst 2012; 104: 764-77.

19. Ezziddin S, Logvinski T, Yong-Hing C, et al. Factors predicting tracer uptake in somatostatin receptor and MIBG scintigraphy of metastatic gastroenteropancreatic neuroendocrine tumors. J Nucl Med 2006; 47: 223-33.

20. Montravers F, Kerrou K, Nataf V, et al. Impact of fluorodihydroxyphenylalanine- $18 \mathrm{~F}$ positron emission tomography on management of adult patients with documented or occult digestive endocrine tumors. J Clin Endocrinol Metab 2009; 94: 1295-301.

21. Gabriel M, Decristoforo C, Kendler D, et al. 68GaDOTA-Tyr3-octreotide PET in neuroendocrine tumors: comparison with somatostatin receptor scintigraphy and CT. J Nucl Med 2007; 48: 508-18.

22. Buchmann I, Henze M, Engelbrecht S, et al. Comparison of 68Ga-DOTATOC PET and 111/n-DTPAOC (Octreoscan) SPECT in patients with neuroendocrine tumours. Eur J Nucl Med Mol Imaging 2007; 34: 1617-26.

23. Gibril F, Jensen RT. Diagnostic uses of radiolabelled somatostatin receptor analogues in gastroenteropancreatic endocrine tumours. Dig Liver Dis 2004; 36: S106-20.

24. Ekeblad S, Skogseid B, Dunder K, Oberg K, Eriksson B. Prognostic factors and survival in 324 patients with pancreatic endocrine tumor treated at a single institution. Clin Cancer Res 2008; 14: 7798-803.

25. Tang L, Shia J, Vakiani E, et al. High grade transformation of differentiated neuroendocrine neoplasms (NENs) of the enteropancreatic system, a unique entity distinct from de novo high grade neuroendocrine carcinoma (HGNECa) in pathogenesis and clinical behavior. Mod Pathol 2008; 21: 137A. 
26. Binderup T, Knigge U, Loft A, Federspiel B, Kjaer A. 18F-fluorodeoxyglucose positron emission tomography predicts survival of patients with neuroendocrine tumors. Clin Cancer Res 2010; 16: 978-85.

27. Koopmans KP, Neels OC, Kema IP, et al. Improved staging of patients with carcinoid and islet cell tumors with 18F-dihydroxy-phenyl-alanine and 11C-5-hydroxy-tryptophan positron emission tomography. J Clin Oncol 2008; 26: 1489-95.

28. Haug A, Auernhammer CJ, Wängler B, et al. Intraindividual comparison of 68Ga-DOTA-TATE and 18F-DOPA PET in patients with well-differentiated metastatic neuroendocrine tumours. Eur J Nucl Med Mol Imaging 2009; 36: 765-70.

29. Yalcin S, Oyan B, Bayraktar Y. Current medical treatment of pancreatic neuroendocrine tumors. Hepatogastroenterology 2007; 54: 278-84.

30. Bilimoria KY, Bentrem DJ, Merkow RP, et al. Application of the pancreatic adenocarcinoma staging system to pancreatic neuroendocrine tumors. J Am Coll Surg 2007 205: 558-63.

31. Givi B, Pommier SJ, Thompson AK, et al. Operative resection of primary carcinoid neoplasms in patients with liver metastases yields significantly better survival. Surgery 2006; 140: 891-7; discussion 897-8.

32. Hung JS, Chang MC, Lee PH, Tien YW. Is surgery indicated for patients endocrine with symptomatic nonfunctioning pancreatic neuroendocrine tumor and unresectable hepatic metastases? World J Surg 2007; 31: 2392-7.

33. Mansour JC, Chen H. Pancreatic endocrine tumors. J Surg Res 2004; 120: 139-61.

34. Strosberg JR, Coppola D, Klimstra DS, et al. The NANETS Consensus Guidelines for the diagnosis and management of poorly differentiated (high-grade) extrapulmonary neuroendocrine carcinomas. Pancreas 2010; 39 799-800.

35. Blonski WC, Reddy KR, Shaked A, Siegelman E, Metz DC Liver transplantation for metastatic neuroendocrine tumor: a case report and review of the literature. World J Gastroenterol 2005; 11: 7676-83.

36. Coppa J, Pulvirenti A, Schiavo M, et al. Resection versus transplantation for liver metastases from neuroendocrine tumors. Transplant Proc 2001; 33: 1537-9.

37. Hellman P, Ladjevardi S, Skogseid B, Akerström G, Elvin $A$. Radiofrequency tissue ablation using cooled tip for liver metastases of endocrine tumors. World I Surg 2002; 26: 1052-6.

38. Henn AR, Levine EA, McNulty W, Zagoria RJ. Percutaneous radiofrequency ablation of hepatic metastases for symptomatic relief of neuroendocrine syndromes. AJR Am J Roentgenol 2003; 181: 1005-10.

39. Elvin A, Skogseid B, Hellman P. Radiofrequency ablation of neuroendocrine liver metastases. Abdom Imaging 2005; 30: 427-34.

40. Gillams A, Cassoni A, Conway G, Lees W. Radiofrequency ablation of neuroendocrine liver metastases: the Middlesex experience. Abdom Imaging 2005; 30: 435-41.

41. Bilchik AJ, Sarantou T, Foshag LJ, Giuliano AE, Ramming KP. Cryosurgical palliation of metastatic neuroendocrine tumors resistant to conventional therapy. Surgery 1997; 122: 1040-7; discussion 1047-8.

42. Kamat PP, Gupta S, Ensor JE, et al. Hepatic arterial embolization and chemoembolization in the management of patients with large-volume liver metastases. Cardiovasc Intervent Radiol 2008; 31: 299-307.

43. Gupta S, Johnson MM, Murthy R, et al. Hepatic arterial embolization and chemoembolization for the treatment of patients with metastatic neuroendocrine tumors: variables affecting response rates and survival. Cancer 2005; 104: 1590-602.

44. Venook AP. Embolization and chemoembolization therapy for neuroendocrine tumors. Curr Opin Oncol 1999; 11: 38-41.

45. Roche A, Girish BV, de Baère T, et al. Transcatheter arterial chemoembolization as first-line treatment for hepatic metastases from endocrine tumors. Eur Radiol 2003; 13: 136-40.

46. Cao CQ, Yan TD, Bester L, Liauw W, Morris DL. Radioembolization with yttrium microspheres for neuroendocrine tumour liver metastases. Br I Surg 2010; 97: 537-43.

47. Kennedy AS, Dezarn WA, McNeillie P, et al. Radioembolization for unresectable neuroendocrine hepatic metastases using resin 90Y-microspheres: early results in 148 patients. Am J Clin Oncol 2008; 31: 271-9.

48. King J, Quinn R, Glenn DM, et al. Radioembolization with selective internal radiation microspheres for neuroendocrine liver metastases. Cancer 2008; 113: 921-9.

49. Rhee TK, Lewandowski RJ, Liu DM, et al. 90Y Radioembolization for metastatic neuroendocrine liver tumors: preliminary results from a multi-institutional experience. Ann Surg 2008; 247: 1029-35.

50. Van Essen M, Krenning EP, De Jong M, Valkema R, Kwekkeboom DJ. Peptide receptor radionuclide therapy with radiolabelled somatostatin analogues in patients with somatostatin receptor positive tumours. Acta Oncol 2007; 46: 723-34

51. Srirajaskanthan R, Toumpanakis C, Meyer T, Caplin ME. Review article: future therapies for management of metastatic gastroenteropancreatic neuroendocrine tumours. Aliment Pharmacol Ther 2009; 29: 1143-54.

52. Keskin O, Yalcin S. A review of the use of somatostatin analogs in oncology. Onco Targets Ther 2013; 6: 471-83.

53. Kvols LK, Moertel CG, O'Connell MJ, et al. Treatment of the malignant carcinoid syndrome. Evaluation of a long-acting somatostatin analogue. N Engl J Med 1986; 315: 663-6.

54. Wymenga AN, Eriksson B, Salmela PI, et al. Efficacy and safety of prolonged-release lanreotide in patients with gastrointestinal neuroendocrine tumors and hormone-related symptoms. J Clin Oncol 1999; 17: 1111-7.

55. Oberg K, Funa K, Alm G. Effects of leukocyte interferon on clinical symptoms and hormone levels in patients with mid-gut carcinoid tumors and carcinoid syndrome. N Engl J Med 1983; 309: 129-33.

56. Woodside KJ, Townsend CM Jr, Mark Evers B. Current management of gastrointestinal carcinoid tumors. J Gastrointest Surg 2004; 8: 742-56.

57. Anthony LB, Pavel ME, Hainsworth JD, et al. Impact of previous somatostatin analogue use on the activity of everolimus in patients with advanced neuroendocrine tumors: analysis from the phase III RADIANT-2 trial. Neuroendocrinology 2015; 102: 18-25.

58. Eriksson B, Oberg K. Summing up 15 years of somatostatin analog therapy in neuroendocrine tumors: future outlook. Ann Oncol 1999; 10: S31-8.

59. Shah T, Caplin M. Endocrine tumours of the gastrointestinal tract. Biotherapy for metastatic endocrine tumours. Best Pract Res Clin Gastroenterol 2005; 19: 617-36.

60. Rinke A, Müller HH, Schade-Brittinger C, et al. Placebocontrolled, double-blind, prospective, randomized study on the effect of octreotide LAR in the control of tumor growth in patients with metastatic neuroendocrine midgut tumors: a report from the PROMID Study Group. J Clin Oncol 2009; 27: 4656-63. 
61. Caplin M, Pavel M, et al. Lanreotide in Metastatic Enteropancreatic Tumor Neuroendocrine Tumors. N Engl J Med 2014 ; 371 : 224-33 Efficacy of Everolimus Alone or in Combination With Pasireotide LAR in Advanced PNET (COOPERATE-1) http://clinicaltrials.gov/show/ NCT01374451

62. Oberg K, Eriksson B. The role of interferons in the management of carcinoid tumours. Br J Haematol 1991; 79: 74-7.

63. Faiss S, Pape UF, Böhmig $M$, et al. Prospective, random ized, multicenter trial on the antiproliferative effect of lanreotide, interferon alfa, and their combination for therapy of metastatic neuroendocrine gastroenteropancreatic tumors: the International Lanreotide and Interferon Alfa Study Group. J Clin Oncol 2003; 21 : 2689-96.

64. Murray-Lyon IM, Eddleston AL, Williams R, et al. Treat ment of multiple-hormone-producing malignant islet cell tumor with streptozotocin. Lancet 1968; 2: 895-8.

65. Moertel CG, Lavin PT, Hahn RG, et al. Phase II trial of doxorubicin for advanced islet cell carcinoma. Cancer 1982; 61: 1567-9.

66. Ramanathan RK, Cnaan RG, Hahn G, et al. Phase II tri al of dacarbazine (DTIC) in advanced pancreatic islet cell carcinoma. Study of Eastern Cooperative Oncology Group - E6282. Ann Oncol 2001; 12: 1139-43.

67. Middleton MR, Grob JJ Aaronsson N, et al. Randomized phase III study of temozolomide versus dacarbazine in the treatment of patients with advanced metastatic melanoma. J Clin Oncol 2000; 18: 158-66.

68. Ekeblad S, Sundin A, Janson ET, et al. Temozolomide as monotherapy is effective in treatment of advanced malignant neuroendocrine tumors. Clin Cancer Res 2007; 13: 2986-91.

69. Kulke MH, Kim H, Clark JW, et al. A phase II trial of gemcitabine for metastatic neuroendocrine tumors. Cancer 2004; 101: 934-9.

70. Bongiovanni A, Riva N, Calpona S, et al. Metronomic capecitabine in gastroenteropancreatic neuroendrocrine tumors: a suitable regimen and review of the literature. Onco Targets Ther 2014; 7: 1919-26.

71. Moertel CG, Lefkopoulo M, Lipsitz S, Hahn RG, Klaassen D. Streptozocin-doxorubicin, streptozocin-fluorouracil or chlorozotocin in the treatment of advanced islet-cell carcinoma. N Engl J Med 1992; 326: 519-23.

72. Rivera E, Ajani JA. Doxorubicin, streptozocin, and 5-fluorouracil chemotherapy for patients with metastatic islet-cell carcinoma. Am J Clin Oncol 1998; 21: 36-8.

73. Moertel CG, Hanley JA, Johnson LA. Streptozocin alone compared with streptozocin plus fluorouracil in the treatment of advanced islet-cell carcinoma. N Engl J Med 1980; 303: 1189-94.

74. Strosberg JR, Fine RL, Choi J, et al. First-line chemotherapy with capecitabine and temozolomide in patients with metastatic pancreatic endocrine carcinomas. Cancer 2011; 117: 268-75.

75. Kulke MH, Stuart K, Earle CC, et al. A phase II study of temozolomide and bevacizumab in patients with advanced neuroendocrine tumors. J Clin Oncol (Meeting Abstracts) 2006; 24 (18 Suppl.): 4044.

76. Fine RL, Gulati AP, Tsushima D, et al. Prospective phase II study of capecitabine and temozolomide (CAPTEM) for progressive, moderately, and well-differentiated metastatic neuroendocrine tumors. J Clin Oncol 2014; 32 (Suppl 3): Abstract 179.

77. Mitry E, Baudin E, Ducreux M, et al. Treatment of poorly differentiated neuroendocrine tumours with etoposide and cisplatin. Br J Cancer 1999; 81: 1351-5.
78. Fjällskog ML, Granberg DP, Welin SL, et al. Treatment with cisplatin and etoposide in patients with neuroendocrine tumors. Cancer 2001; 92: 1101-7.

79. Welin S, Sorbye H, Sebjornsen S, et al. Clinical effect of temozolomide-based chemotherapy in poorly differentiated endocrine carcinoma after progression on first-line chemotherapy. Cancer 2011; 11: 4617-22.

80. Hentic O, Hammel P, Couvelard A, et al. FOLFIRI regimen: an effective second-line chemotherapy after failure of etoposide-platinum combination in patients with neuroendocrine carcinomas grade 3 . Endocr Relat Cancer 2012; 19: 751-7.

81. Yao JC, Phan AT, Chang DZ, et al. Efficacy of RAD001 (everolimus) and octreotide LAR in advanced low- to intermediate-grade neuroendocrine tumors: results of a phase II study. J Clin Oncol 2008; 26: 4311-8.

82. Pavel ME, Hainsworth JD, Baudin E, et al. Everolimus plus octreotide long-acting repeatable for the treatment of advanced neuroendocrine tumours associated with carcinoid syndrome (RADIANT-2): a randomised, placebo-controlled, phase 3 study. Lancet 2011; 378: 2005-12.

83. Yao JC, Shah $\mathrm{MH}$, Ito $\mathrm{T}$, et al. Everolimus for advanced pancreatic neuroendocrine tumors. N Engl J Med 2011; 364: 514-23.

84. Raymond E, Dahan L, Raoul JL, et al. Sunitinib malate for the treatment of pancreatic neuroendocrine tumors. N Engl J Med 2011; 364: 501-13.

85. Kulke MH, Lenz HJ, Meropol NJ, et al. Activity of sunitinib in patients with advanced neuroendocrine tumors. J Clin Oncol 2008; 26: 3403-10.

86. Phan AT, Halperin DM, Chan JA, et al. Pazopanib and depot octreotide in advanced, well-differentiated neuroendocrine tumours: a multicentre, single-group, phase 2 study. Lancet Oncol 2015; 16: 695-703.

87. Pulido EG, Castellano DE, Garcia-Carbonero R, et al. PAZONET: Results of a phase II trial of pazopanib as a sequencing treatment in progressive metastatic neuroendocrine tumors (NETs) patients (pts), on behalf of the Spanish task force for NETs (GETNE) - NCT01280201. J Clin Oncol (Meeting Abstracts) 2012; 30: 4119.

88. Hobday TJ, Rubin J, Holen K, et al. MC044h, a phase II trial of sorafenib in patients (pts) with metastatic neuroendocrine tumors (NET): A Phase II Consortium (P2C) study. J Clin Oncol (Meeting Abstracts) 2007; 25 (18 Suppl.): 4504.

89. Hobday TJ, Holen K, Donehower R, et al. A phase II trial of gefitinib in patients (pts) with progressive metastatic neuroendocrine tumors (NET): A Phase II Consortium (P2C) study. J Clin Oncol (Meeting Abstracts) 2006; 24 (18 Suppl): 4043.

90. Song Z, Zhang Y. Efficacy of gefitinib or erlotinib in patients with squamous cell lung cancer. Arch Med Sci 2015; 11: 164-8.

91. Gross DJ, Munter G, Bitan M, et al. The role of imatinib mesylate (Glivec) for treatment of patients with malignant endocrine tumors positive for c-kit or PDGF-R. Endocr Relat Cancer 2006; 13: 535-40.

92. Yao JC, Zhang JX, Rashid A, et al. Clinical and in vitro studies of imatinib in advanced carcinoid tumors. Clin Cancer Res 2007; 13: 234-40.

93. Anthony L, Chester M, Michael S, O’Dorisio TM, O’Dorisio MS. Phase II open-label clinical trial of vatalanib (PTK/ZK) in patients with progressive neuroendocrine cancer. J Clin Oncol (Meeting Abstracts) 2008; 26 (15 Suppl): 14624.

94. Pavel ME, Bartel C, Heuck F, et al. Open-label, non-randomized, multicenter phase II study evaluating the angiogene- 
sis inhibitor PTK787/ ZK222584 (PTK/ZK) in patients with advanced neuroendocrine carcinomas (NEC). J Clin Oncol (Meeting Abstracts) 2008; 26 (15 Suppl.): 14684.

95. Yao JC, Phan A, Hoff PM, et al. Targeting vascular endothelial growth factor in advanced carcinoid tumor: a random assignment phase II study of depot octreotide with bevacizumab and pegylated interferon alpha- $2 b$. J Clin Oncol 2008; 26: 1316-23.

96. Arnold R, Chen YJ, Frederico Costa F, et al. ENETS Consensus Guidelines for the standards of care in neuroen docrine tumors: follow-up and documentation. Neuroendocrinology 2009; 90: 227-33.

97. Wang L, Tang K, Zhang Q, et al. Somatostatin receptor-based molecular imaging and therapy for neuroendocrine tumors. BioMed Res Inter 2013; 2013: 102819. 